\title{
EVALUASI DESAIN ANTARMUKA SISTEM INFORMASI BENCANA MENGGUNAKAN ATURAN THEO MANDEL
}

\author{
I Gede Surya Rahayuda*1, Ni Putu Linda Santiari ${ }^{2}$ \\ ${ }^{12}$ Prodi Sistem Informasi, Fakultas Informatika dan Komputer, Institut Teknologi dan Bisnis STIKOM Bali

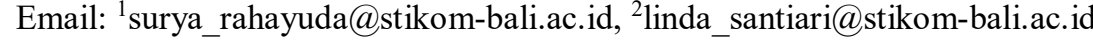 \\ *Penulis Korespondensi
}

(Naskah masuk: 20 November 2020, diterima untuk diterbitkan: 09 Juni 2021)

\begin{abstract}
Abstrak
Desain antarmuka merupakan hal yang penting dalam pengembangan aplikasi sistem informasi, dengan terbentuknya desain antarmuka yang baik maka akan dihasilkan suatu aplikasi yang memiliki nilai usability yang tinggi dan akan dapat meningkatkan pengalaman pengguna. Pada penelitian ini akan dilakukan evaluasi terhadap sebuah simulasi sistem informasi bencana berbasis website, dimana website dibangun menggunakan material desain vuetify.js. Vuetify merupakan sebuah library user interface dari front end framework yang memiliki desain antarmuka yang baik yaitu vue.js. Evaluasi dilakukan menggunakan Mandel's Golden Rules, dimana aturan tersebut memiliki tiga kelompok kriteria evaluasi dan tiap kelompok memiliki beberapa poin evaluasi, seperti 10 aturan evaluasi pada kelompok place users in control, 9 aturan evaluasi pada kelompok reduce users memory load dan 5 aturan evaluasi pada kelompok make the interface consistent. Sehingga secara keseluruhan terdapat sebanyak 24 aturan evaluasi. Berdasarkan evaluasi yang dilakukan dapat disimpulkan bahwa desain antarmuka dari website yang dibuat secara umum telah sesuai dengan aturan emas Theo Mandel. Dari 24 aturan evaluasi yang dinilai terdapat 9 aturan evaluasi mendapatkan nilai sangat baik dan 15 aturan mendapatkan nilai baik. Dengan total persentase nilai sebesar $79 \%$ (baik).
\end{abstract}

Kata kunci: User Interface, User Experience, Vue.js, Vuetify.js, Theo Mandel, Golden Rules

\section{USER INTERFACE EVALUATION OF DISASTER IFORMATION SYSTEM USING MANDEL'S GOLDEN RULES}

\begin{abstract}
Interface design is important in information system application development, with the formation of a good interface design, an application that has a high usability value will be produced and will be able to improve the user experience. This research will evaluate a website-based disaster information system simulation, where the website is built using the vuetify.js design material. Vuetify is a user interface library from the front end framework which is known for its good interface design, vue.js. Evaluation is carried out using Mandel's Golden Rules, where these rules have three groups of evaluation criteria and each group has several evaluation points, such as 10 evaluation rules in the place users in control group, 9 evaluation rules in the reduce users memory load group and 5 evaluation rules in the make group the interface consistent. So that in total there are 24 evaluation rules. Based on the evaluation, it can be concluded that the interface design of the website is generally in accordance with Theo Mandel's golden rules. Of the 24 evaluation rules that are assessed, there are 9 evaluation rules that get very good scores and 15 rules get good scores. With a total percentage value of $79 \%$ (good).
\end{abstract}

Keywords: User Interface, User Experience, Vue.js, Vuetify.js, Theo Mandel, Golden Rules

\section{PENDAHULUAN}

Permasalahan desain antarmuka kerap terjadi pada pengembangan sebuah program sistem informasi. Tanpa disadari permasalahan sering ditemukan pada saat program sudah selesai dikembangkan baik oleh admin atau user. Misalkan seperti permasalahan sistem navigasi, tombol, icon, footer, gambar dan lainnya. Permasalahan tersebut sering berakibat pada kerugian material dan waktu, karena harus mengeluarkan dana dan waktu lebih untuk pembuatan ulang atau perbaikan (Yasin and Yumarlin, 2016). Karena permasalahan tersebut maka perlu dilakukan evaluasi terhadap desain antarmuka sistem informasi sebelum sistem tersebut 
didistribusikan. Desain antarmuka atau user interface design (UI) merupakan bagian visual dari perangkat lunak atau perangkat keras yang memastikan bagaimana seorang pengguna berinteraksi dengan perangkat lunak atau perangkat keras tersebut serta bagaimana data dan informasi ditampilkan (Tabandehpour, 2019)(Abulfaraj and Steele, 2020). User interface atau desain antarmuka merupakan tempat dimana dua sistem independen bertemu dan berkomunikasi. Penyajian, navigasi, dan interaksi informasi antara sistem komputer dan pengguna (Suatkab and Santoso, 2018). Tujuan dari desain antarmuka adalah untuk meningkatkan usability dan juga pengalaman pengguna atau user experience (UX) (Ruiz and Serral, 2020). Tampilan desain antarmuka yang baik dan konsisten akan membuat pengguna lebih mudah memahami desain antarmuka dari perangkat lunak yang dibuat. Misalkan sebuah website jurnal yang dikembangkan pada tiap universitas, jika sistem informasi tersebut menggunakan desain antarmuka yang konsisten, maka pengguna yang sudah pernah mengakses website tersebut pada universitas A akan memiliki user experience dan akan lebih mudah memahami jika akan mengakses website jurnal baru pada universitas B. Pada penelitian ini penulis akan membahas mengenai evaluasi user interface (UI) pada website simulasi sistem informasi bencana yang telah dikembangkan sebelumnya (Dianata and Adelia, 2019). Pada penelitian sebelumnya penulis menggunakan evaluasi blackbox testing, evaluasi tersebut lebih mengutamakan bagaimana kinerja dari tiap halaman atau fiture perangkat lunak. Pada penelitian saat ini penulis lebih mengutamakan pada evaluasi desain antarmuka dari sistem yang telah dibuat, maksud dari penulis adalah menambahkan dengan evaluasi dari sudut pandang lainnya, khususnya pada desain antarmuka. Dimana desain antarmuka dibangun menggunakan framework vuetify.js. Framework vuetify.js merupakan salah satu variasi atau pengembangan dari front end framework vue.js. Vuetify merupakan user interface (UI) library dengan komponen buatan tangan yang indah dan merupakan pustaka komponen pertama untuk vue.js dan aktif dikembangkan sampai saat ini
(Carlos, 2019). Evaluasi desain antarmuka akan dilakukan sesuai dengan aturan emas Theo Mandel (Dianata and Adelia, 2019). Aturan emas mengenai user interface merupakan aturan yang sudah ada cukup lama dan dikembangkan oleh berbagai ilmuwan. Penulis memilih menggunakan aturan emas Theo Mandel karena aturan tersebut sangat sesuai digunakan untuk evaluasi perangkat lunak berbasis website (Yasin and Yumarlin, 2016). Penulis berharap desain antarmuka dari website yang telah dirancang sebelumnya sesuai dengan aturan emas Theo Mandel dan mendapatkan hasil evaluasi yang baik.

\section{METODE PENELITIAN}

Metode penelitian dilakukan dalam beberapa langkah dimulai dari mempersiapkan user interface yang akan diuji, yaitu: Halaman Home, Fire Incidents, Fire Stations, Pathfinding, Contact dan Questions. Kemudian dilakukan evaluasi sesuai dengan aturan Mandel's golden rules (Amini, Pradnyana and Wirawan, 2019). Dimana evaluasi akan dilakukan oleh beberapa responden dengan cara menyebarkan kuisioner. Kuisioner akan dibuat menggunakan form dan disebarkan secara online kepada 30 responden dari mahasiswa, pada kuisioner tersebut akan berisi alamat url web, user interface apa saja yang akan diuji dan beberapa pertanyaan mengenai Mandel's golden rules, apakah user interface web sudah sesuai dengan aturan tersebut atau tidak. Responden dapat memberikan jawaban berupa 5 kisaran range, seperti: sangat baik (5 poin), baik ( 4 poin), sedang ( 3 poin), kurang ( 2 poin) dan sangat kurang (1 poin).

Tabel 1. Skala penilaian

\begin{tabular}{lll}
\hline Ket. & Poin & Range \\
\hline Sangat Baik & 5 poin & $80 \% \leq$ nilai $<100 \%$ \\
Baik & 4 poin & $60 \% \leq$ nilai $<80 \%$ \\
Sedang & 3 poin & $40 \% \leq$ nilai $<60 \%$ \\
Kurang & 2 poin & $20 \% \leq$ nilai $<40 \%$ \\
Sangat Kurang & 1 poin & $0 \% \leq$ nilai $<20 \%$ \\
\hline
\end{tabular}

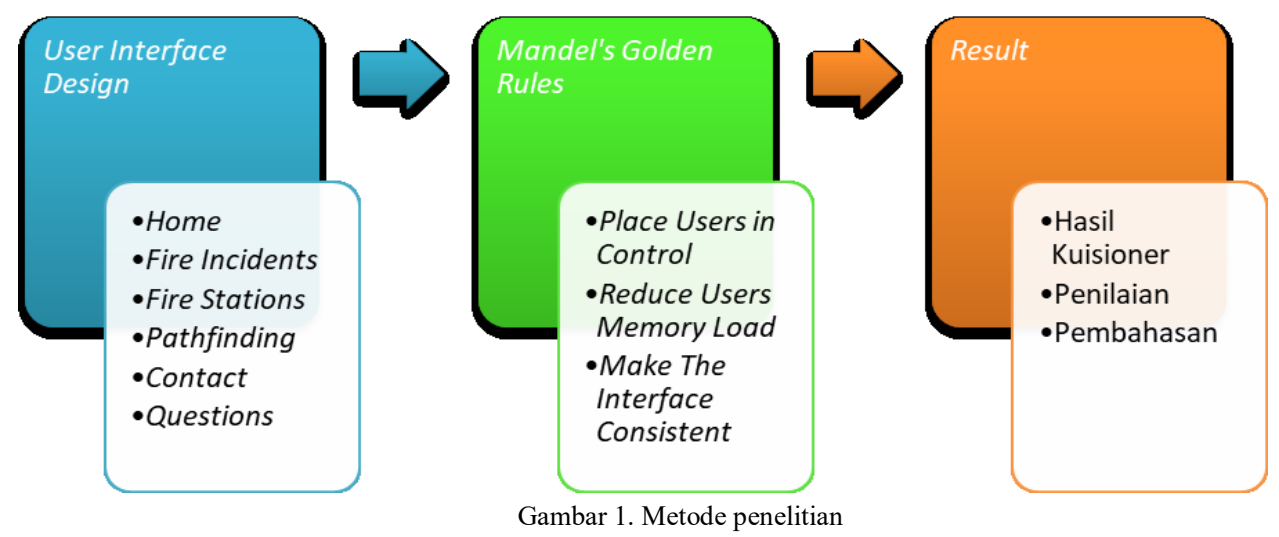


Dari jawaban semua responden tersebut akan dikumpulkan dan kemudian akan dikalkulasi untuk didapatkan rata - rata nilai dari kesesuaian user interface web dengan aturan Mandel's golden rules (Suatkab and Santoso, 2018). Seperti terlihat pada gambar 1. Dari ilustrasi tersebut dapat dilihat bahwa terdapat tiga kelompok evaluasi utama pada aturan emas Mandel's. Dimana pada tiap kelompok tersebut terdapat beberapa poin kriteria yang harus dipehuni dalam merancang atau membuat desain antarmuka pengguna (Wardani, Darmawiguna and Sugihartini, 2019)(Nento, 2019). Tiga kelompok dan beberapa poin tersebut adalah:

\subsection{Place Users in Control}

Rangkaian prinsip pertama membahas penempatan pengguna pada kendali antarmuka. Sebuah analogi untuk prinsip ini adalah membiarkan pengguna mengendarai mobil daripada memaksa mereka naik kereta. Di dalam mobil, pengguna mengontrol arah, navigasi, dan tujuan akhir mereka sendiri. Beberapa prinsip dari place users in control:

- Modeless

Menggunakan mode dengan bijaksana.

- Flexible

User interface yang dibuat agar dapat digunakan pada berbagai perangkat, seperti keyboard dan mouse pada komputer, touchpad pada laptop dan touchscreen pada ponsel atau perangkat dengan layer sentuh. Begitu juga dengan inputan lainnya seperti fingerprint, speech to text dan lainnya.

- Interruptible

User interface desain yang dibuat memperbolehkan pengguna untuk mengubah fokus. Pengguna dapat mengakses aplikasi lainnya bersamaan saat mengakses web yang dibuat. Web tidak mengalami gangguan atau error ketika pengguna mengubah fokus.

- Helpful

Tampilan pesan dan teks deskriptif atau bermanfaat. Pesan dan teks yang dituliskan pada website dapat memberikan manfaat bagi pengguna yang membacanya, baik berupa data, informasi dan lainnya.

- Forgiving

User interface yang dibuat dapat memberikan tindakan segera, reversible dan umpan balik. Agar memberikan kesan memaafkan bagi pengguna. Seperti tombol yang menanyakan kembali apakah anda yakin, dan memberikan pilihan ok dan cancel atau seperti pada menu login yang menyediakan menu forget password.

- Navigable

User interface memberikan jalur navigasi yang baik, keluar atau masuk sistem, back dan next, navigasi lengkap dan tersedia pada setiap halaman.
- Accessible

User interface dapat diakses oleh pengguna dari berbagai tingkat keahlian, pengguna dengan user experience rendah maupun tinggi dan pengguna dari berbagai kalangan dapat mengakses.

- Facilitative

Menjadikan user interface transparan.

- Preferences

Memberikan akses kepada pengguna untuk menyesuaikan antarmuka.

- Interactive

Memperbolehkan pengguna untuk secara langsung memanipulasi objek antarmuka.

\subsection{Reduce Users Memory Load}

Antarmuka harus membantu pengguna mengingat informasi saat menggunakan komputer hal ini dapat menanggulangi keterbatasan memori manusia dan sistem persepsi. Elemen program seperti tindakan urungkan, ulangi dan papan klip seperti potong, salin, dan tempel memungkinkan pengguna untuk memanipulasi potongan informasi yang dibutuhkan di banyak tempat dalam file aplikasi dan di seluruh aplikasi. Mengisi formulir online dengan informasi umum seperti nama, alamat, dan nomor telepon sebaiknya diingat oleh sistem setelah pengguna memasukkannya atau setelah catatan pelanggan disimpan. Antarmuka mendukung pengambilan memori jangka panjang dengan menyediakan item bagi pengguna untuk dikenali daripada harus mengingat informasi. Beberapa prinsip dari reduce user's memory load:

- Remember

Meringankan ingatan jangka pendek.

- Recognition

Mengandalkan pengenalan, pengertian bukan ingatan.

- Inform

Memberikan isyarat visual, informasi yang diberikan dapat berupa gambar, icon atau warna.

- Forgiving

Memberikan toleransi kesalahan, seperti undo, redo dan default.

- Frequency

Memberikan pintasan antarmuka, pengguna dapat dengan mudah mengakses informasi yang ingin dikases tanpa harus menelusuri web jauh kedalam mengikuti sistem navigasi.

- Intuitive

Menawarkan sintak aksi objek.

- Transfer

Menggunakan metafora dunia nyata.

- Context

Pengungkapan progresif pengguna.

- Organize

Menawarkan kejelasan visual. 


\subsection{Make the Interface Consistent}

Konsistensi user interface adalah elemen kunci dari antarmuka yang dapat digunakan. Namun, konsistensi tidak boleh dilihat sebagai hanya area kritis dari desain antarmuka. Manfaat konsistensi bagi pengguna untuk mentransfer pengetahuan mereka dan belajar program baru setelah mereka belajar elemen antarmuka umum dari sistem operasi dan program yang sering mereka gunakan. Konsistensi dalam presentasi berarti pengguna harus melihat informasi dengan cara logis, visual, dan fisik yang sama di seluruh produk. Jika satu jenis informasi ditampilkan dan dimasukkan menggunakan kontrol antarmuka tertentu, maka sama kontrol harus digunakan untuk menampilkan dan memasukkan informasi yang sama di seluruh produk. Konsistensi dalam behavior berarti cara kerja elemen antarmuka sama di mana-mana. Perilaku antarmuka kontrol seperti tombol, daftar, dan item menu harus tidak berubah di dalam atau di antara program. Konsistensi dalam teknik interaksi juga penting. Pengguna mengharapkan hasil yang sama ketika mereka berinteraksi dengan cara yang sama dengan elemen antarmuka yang serupa. Antarmuka yang konsisten mendorong pengguna untuk menjelajah. Pengguna harus dapat tanpa takut akan konsekuensi negatif, memilih item dan menavigasi sistem untuk mencari tahu di mana sesuatu berada dan apa yang terjadi ketika mereka melakukan sesuatu. Beberapa prinsip dari make the interface consistent:

- Continuity

Mempertahankan konteks kegiatan pengguna.

- Experience

Mempertahankan konsistensi didalam dan diluar user interface.

- Expectations

Menjaga agar hasil interaksi tetap sama.

- Attitude

Memberikan daya tarik estetika dan sikap

- Predictable

Mendorong explorasi, user interface dapat diprediksi

\section{HASIL DAN PEMBAHASAN}

Penelitian dilakukan sesuai dengan metode penelitian yang digunakan. Beberapa tampilan halaman desain antarmuka yang dinilai adalah seperti gambar 2 .

Halaman home merupakan halaman pertama pada desain antarmuka. Saat pengguna mengakses situs web, maka halaman tersebut yang akan ditampilkan. Pada halaman home terdapat timeline menggunakan teknologi dari vuetify.js dimana jika kursor diarahkan pada salah satu timeline, maka gambar timenline akan tertutup box secara otomatis, kemudian jika ditekan barulah halaman detail akan ditampilkan. Timeline berisi informasi berupa berita mengenai bencana kebakaran pada kota tersebut.

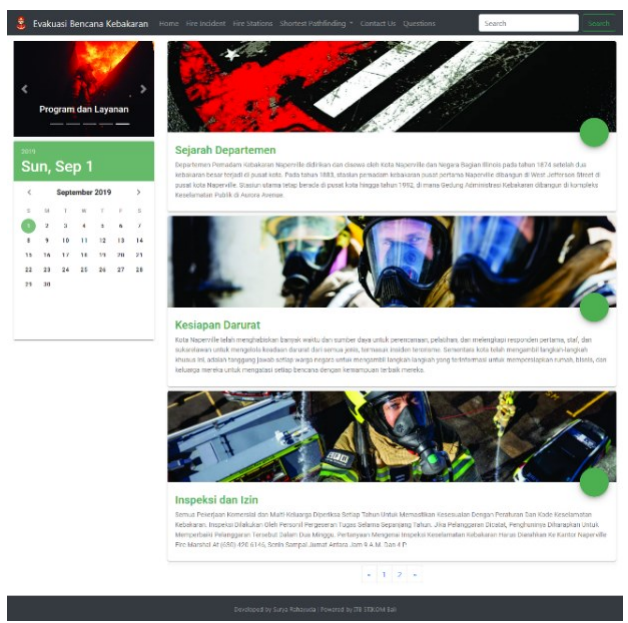

Gambar 2. Halaman home

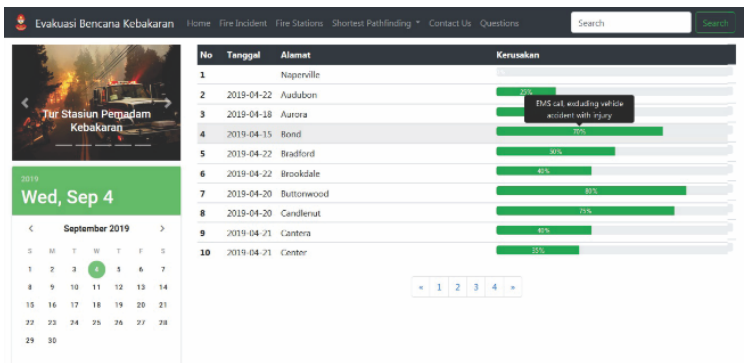

Gambar 3. Halaman fire incident

Halaman kedua adalah halaman fire incident, pada halaman ini terdapat data sampel yang digunakan pada penelitian, data tersebut berupa catatan kejadian kebakaran yang terjadi, seperti tanggal, nama tempat, dan persentase kerusakan. Pada bagian persentase keruskan juga dibuatkan menu tooltip, dimana jika kursor diarahkan maka akan muncul notifikasi mengenai penyebab kebakaran atau kerusakan apa saja yang ditimbulkan oleh bencana tersebut.

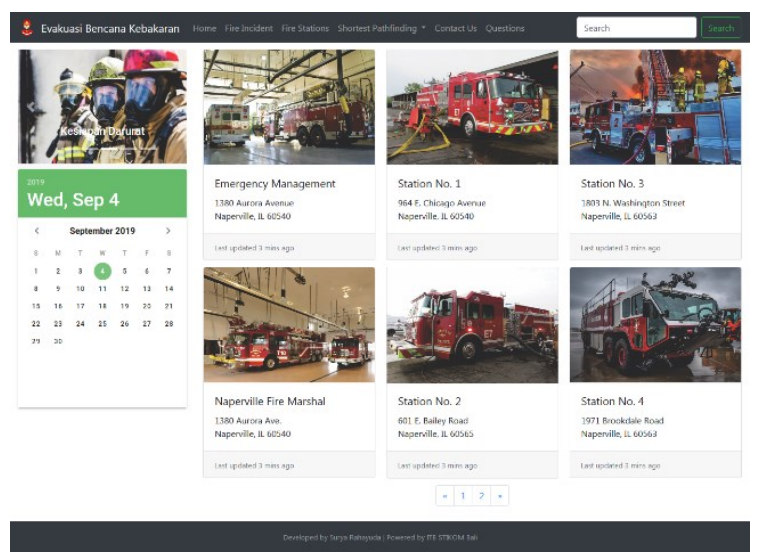

Gambar 4. Halaman fire stations 
Halaman fire stations merupakan halaman yang menampilkan beberapa cabang fire stations yang tersebar pada kota tersebut.

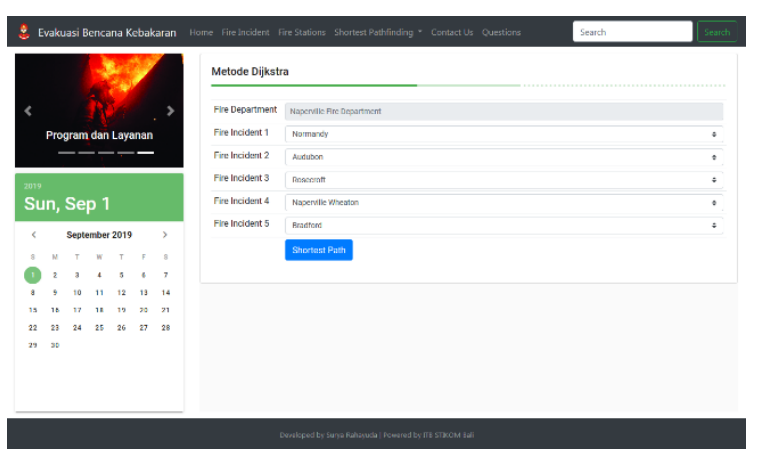

Gambar 5. Halaman submit page metode dijkstra

Halaman pathfinding merupakan halaman utama dari penelitian yang dilakukan, pada halaman ini terdapat dua buah metode pencarian jalur terdekat yaitu Dijkstra dan Bidi-Dijkstra. Pengguna dapat memilih salah satu metode yang digunakan. Setelah melakukan pilihan, akan ditampilkan halaman submit page. Pada halaman tersebut pengguna dapat memilih lokasi kebakaran yang terjadi kemudian menekan tombol submit untuk menentukan rute terdekat (Aryando, Steven and Alwin, 2019)(Bahraen, Rosihan and Abdul, 2018).

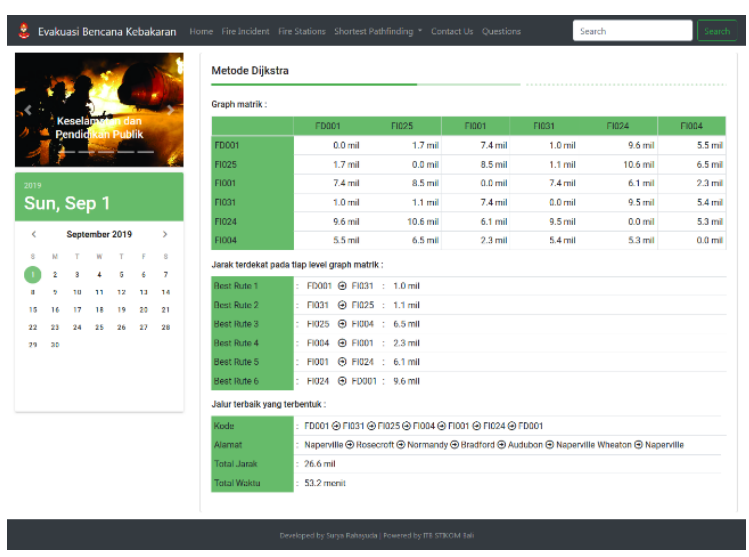

Gambar 6. Halaman result metode dijkstra

Setelah tombol submit ditekan maka akan ditampilkan halaman hasil, pada halaman ini ditampilkan graph matriks dan rute terdekat.

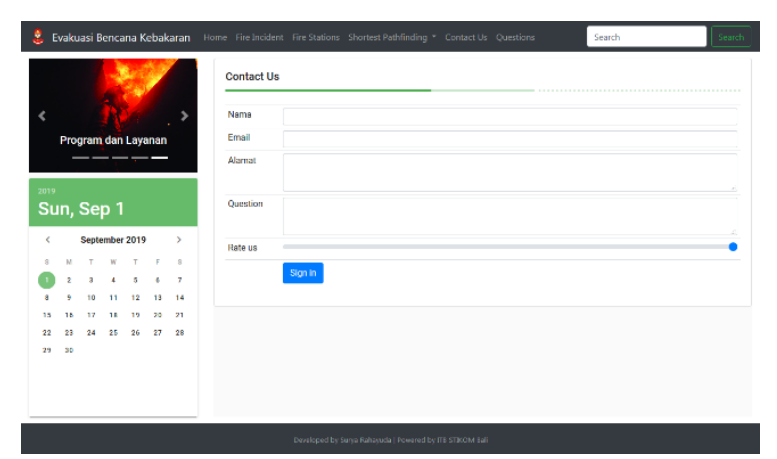

Gambar 7. Halaman contact us
Halaman terakhir merupakan halaman contact us, pada halaman ini pengguna dapat berinteraksi dengan memasukkan data berupa nama, email, alamat, pertanyaan dan rate us. Data tersebut akan tersimpan pada basis data dan kemudian kumpulan data pertanyaan akan ditampilkan pada halaman questions.

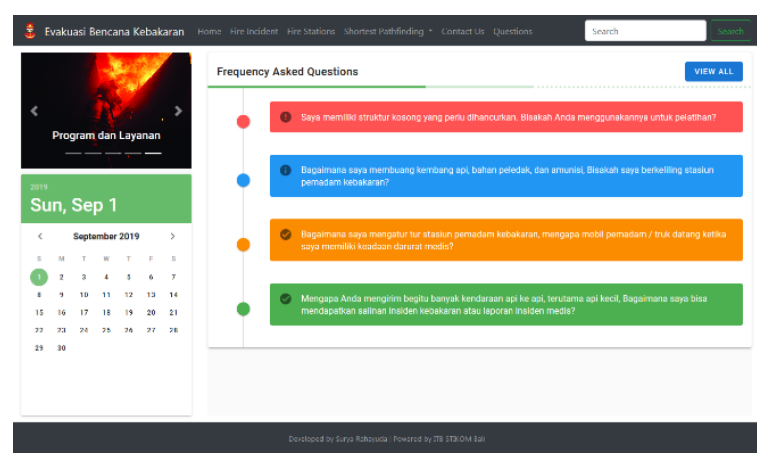

Gambar 8. Halaman questions

Halaman questions merupakan halaman yang menampilkan kumpulan pertanyaan dari pengguna, pada halaman ini digunakan teknologi real time logging dari vuetify.js, dimana setiap pertanyaan akan muncul satu per satu saat tombol view all ditekan tanpa me-refresh browser.

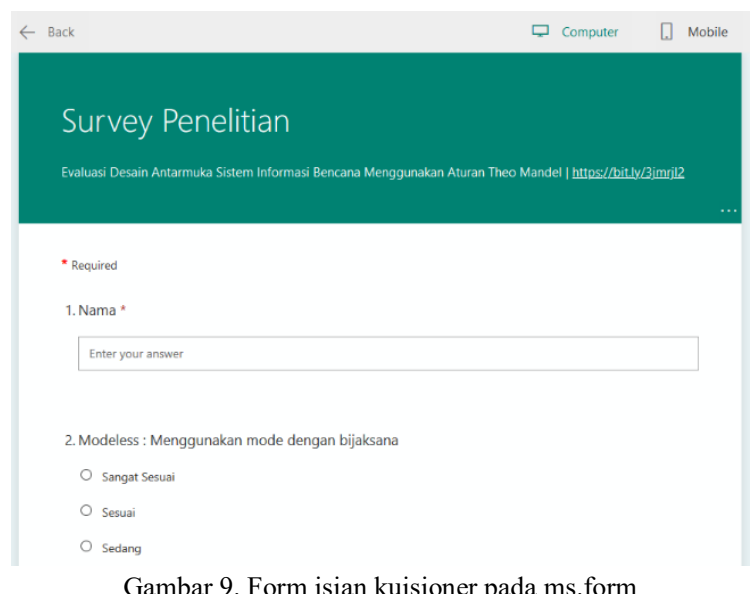

Kuisioner yang telah berisi 24 pertanyaan dan url dari website yang akan dinilai disebarkan kepada beberapa responden. Seperti terlihat pada gambar 9 .

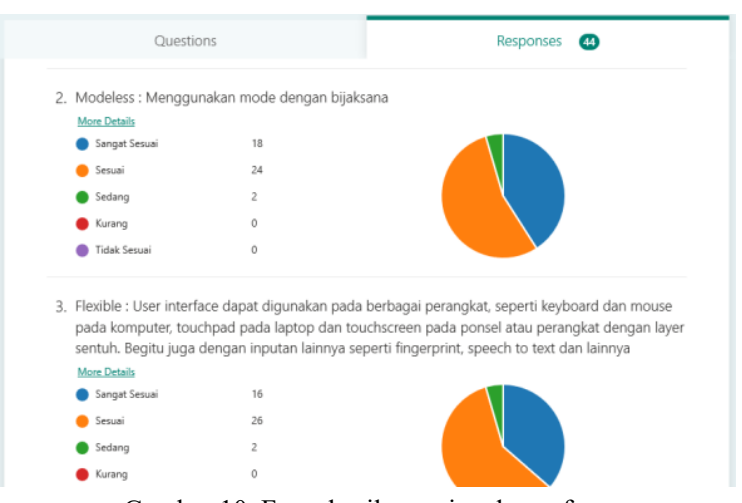

Gambar 10. Form hasil survei pada ms.form 
Berdasarkan penelitian yang dilakukan didapatkan hasil berupa nilai tiap kelompok, nilai tiap aturan dan persentase hubungan antara 5 skala jawaban dan 24 aturan Theo Mandel. Pertama ditampilkan tabel rata nilai berdasarkan jawaban responden yang dikelompokkan dalam 3 grup berdasarkan prinsip aturan Theo Mandel, dari tabel tersebut dapat diketahui persentase hasil jawaban pada tiap grup.

Tabel 2. Nilai rata - rata tiap kelompok

\begin{tabular}{lrrr}
\hline Responden & G. 1 & G. 2 & G. 3 \\
\hline Aryansa Setya N. & $70 \%$ & $71 \%$ & $68 \%$ \\
Putu Didi Pratama & $80 \%$ & $80 \%$ & $72 \%$ \\
Fadhil Afif & $66 \%$ & $67 \%$ & $72 \%$ \\
I Gede Wira A. P. P. & $60 \%$ & $62 \%$ & $60 \%$ \\
I Putu Khrisnandalahari & $74 \%$ & $78 \%$ & $80 \%$ \\
Wayan Adhi Hary P. & $70 \%$ & $71 \%$ & $64 \%$ \\
Agreni Leli kadiwano & $60 \%$ & $60 \%$ & $68 \%$ \\
I Putu Adi Wijaya P. & $64 \%$ & $64 \%$ & $60 \%$ \\
Gede Hendra K. A. & $68 \%$ & $69 \%$ & $64 \%$ \\
Korienti Lado & $68 \%$ & $73 \%$ & $76 \%$ \\
Azrul Muttaqin & $74 \%$ & $69 \%$ & $64 \%$ \\
Putu Gangga & $92 \%$ & $71 \%$ & $76 \%$ \\
Ni Kadek Dwi S. & $86 \%$ & $91 \%$ & $88 \%$ \\
Komang Kresna D. P. & $70 \%$ & $73 \%$ & $76 \%$ \\
Leonarda C. Y. M. & $98 \%$ & $91 \%$ & $92 \%$ \\
Dewa Ayu Ratih Y. P. & $78 \%$ & $78 \%$ & $88 \%$ \\
M. Lelaning Jagad & $82 \%$ & $84 \%$ & $80 \%$ \\
I Putu Adi S. & $90 \%$ & $87 \%$ & $84 \%$ \\
Devin Suardy & $80 \%$ & $78 \%$ & $80 \%$ \\
Dicky Chandra Wijaya & $78 \%$ & $78 \%$ & $80 \%$ \\
I Wayan Artayasa & $96 \%$ & $93 \%$ & $96 \%$ \\
Avellino & $98 \%$ & $89 \%$ & $96 \%$ \\
Gede Esha Windi A. & $88 \%$ & $84 \%$ & $80 \%$ \\
I Nyoman Jodi A.S. & $78 \%$ & $67 \%$ & $60 \%$ \\
Andika Surya & $90 \%$ & $91 \%$ & $92 \%$ \\
Jero Andiarsa & $92 \%$ & $84 \%$ & $80 \%$ \\
Ni Komang Prima H. & $80 \%$ & $80 \%$ & $80 \%$ \\
Kadek Bagus W P. & $92 \%$ & $76 \%$ & $88 \%$ \\
Rafly & $76 \%$ & $73 \%$ & $72 \%$ \\
I Gede Tagel T. & $98 \%$ & $100 \%$ & $100 \%$ \\
\hline Average & $80 \%$ & $78 \%$ & $78 \%$ \\
\hline
\end{tabular}

Tabel kedua ditampilkan nilai rata tiap aturan, pada tabel tersebut dapat diketahui persentase nilai yang diperoleh pada 24 aturan Theo Mandel. Pada tabel juga ditampilkan keterangan nilai, dimana poin tersebut disesuaikan dengan skala jawaban.

Yang terakhir adalah persentase kesesuaian, dimana tabel tersebut merupakan gabungan antaran 24 aturan Theo Mandel dan persentase jawaban dari responden. Persentase ditampilkan dalam bentuk bar chart. Pada chart tersebut dapat diketahui total persentase pilihan jawaban yang diberikan responden pada tiap aturan Theo Mandel.

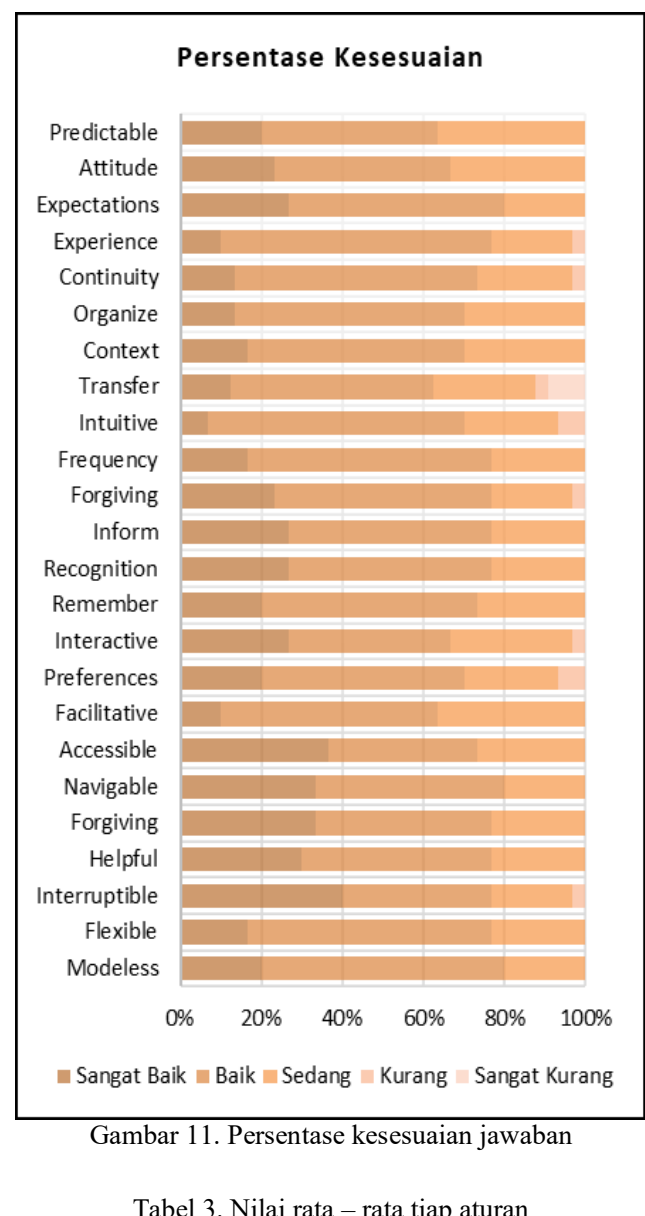

\begin{tabular}{lcl}
\hline Aturan & Rata Nilai & Keterangan \\
\hline Modeless & $80 \%$ & Sangat Baik \\
Flexible & $79 \%$ & Baik \\
Interruptible & $83 \%$ & Sangat Baik \\
Helpful & $81 \%$ & Sangat Baik \\
Forgiving & $82 \%$ & Sangat Baik \\
Navigable & $83 \%$ & Sangat Baik \\
Accessible & $82 \%$ & Sangat Baik \\
Facilitative & $75 \%$ & Baik \\
Preferences & $77 \%$ & Baik \\
Interactive & $78 \%$ & Baik \\
Remember & $79 \%$ & Baik \\
Recognition & $81 \%$ & Sangat Baik \\
Inform & $81 \%$ & Sangat Baik \\
Forgiving & $79 \%$ & Baik \\
Frequency & $79 \%$ & Baik \\
Intuitive & $74 \%$ & Baik \\
Transfer & $74 \%$ & Baik \\
Context & $77 \%$ & Baik \\
Organize & $77 \%$ & Baik \\
Continuity & $77 \%$ & Baik \\
Experience & $77 \%$ & Baik \\
Expectations & $81 \%$ & Sangat Baik \\
Attitude & $78 \%$ & Baik \\
Predictable & $77 \%$ & Baik \\
Average & $79 \%$ & Baik \\
\hline & & \\
\hline
\end{tabular}




\subsection{Hasil Evaluasi Grup 1: Place Users in Control}

Berdasarkan hasil evaluasi terhadap beberapa responden, didapatkan bahwa nilai dari evaluasi kelompok 1 adalah $80 \%$ (sangat baik). User interface website yang dibuat telah sesuai dengan aturan emas kelompok 1 mengenai menempatkan pengguna pada kontrol. Mode yang digunakan sudah baik. User interface flexibilities sudah baik, dengan penggunaan material desain vuetify.js website dapat diakses di berbagai perangkat seperti komputer, laptop, tablet dan ponsel, tampilan tetap stabil menyesuaikan pada tiap perangkat, tombol inputan dan lainnya dapat diakses menggunakan touchscreen atau keyboard (Agustiyo, 2018)(Yasin and Yumarlin, 2016). Interruptible sudah baik, website tetap stabil jika pengguna mengganti fokus pada aplikasi lainnya. Website memiliki nilai helpful yang baik karena data dan informasi yang ditampilkan pada website dapat bermanfaat. Pada poin forgiving, website masih dinilai kurang karena tidak menyediakan forget password dan pertanyaan konfirmasi ulang saat input, delete data dan lainnya. Website sudah sangat navigable, navigasi yang disediakan sangat lengkap, terdapat pada setiap halaman. Website sudah cukup accessible, karena dibangun dengan template yang sederhana dan familiar untuk semua kalangan. Website cukup facilitative dan preferent karena sangat transparan dan pengguna mudah untuk menyesuaikan dengan antarmuka. Mengenai poin interactive, website memiliki nilai yang kurang, karena desain yang dibuat tidak memberikan akses yang cukup pada pengguna untuk memanipulasi atau mengubah objek antarmuka (Ajie, Arief and Amir, 2018).

\subsection{Hasil Evaluasi Grup 2: Reduce Users Memory Load}

Berdasarkan hasil evaluasi terhadap beberapa responden, didapatkan bahwa nilai dari evaluasi kelompok 2 adalah 78\% (baik). User interface website yang dibuat telah sesuai dengan aturan emas kelompok 2 mengenai mengurangi keharusan pengguna untuk mengingat atau menghafal. Pada poin pertama yaitu remember sudah baik, antarmuka yang dibuat telah dirancang agar pengguna mudah untuk mengingat. Recognition dan inform sudah baik, pada website yang dibuat navigasi dibuat minimalis, tombol dibuat berwarna dan beberapa link dibuat dalam gambar. Poin forgiving sudah baik, karena pada website pengguna diberikan toleransi kesalahan, pengguna dapat melakukan undo atau back jika terjadi kesalahan atau ingin mengulangi untuk menulis atau memilih inputan. Frequency sudah baik, pada website telah diberikan berbagai pintasan jika ingin mengakses langsung hal yang ingin diakases. Mengenai poin intuitive dan context memiliki nilai kurang karena pada website tidak menawarkan sintak aksi objek dan pengungkapan progressive pengguna. Poin transfer dan organize memiliki nilai yang baik karena antarmuka menggunakan metafora dunia nyata dan visual yang ditampilkan sudah sangat jelas (Nento, 2019)(Jeffry, Lukito and Rudy, 2017).

\subsection{Hasil Evaluasi Grup 3: Make the Interface Consistent}

Berdasarkan hasil evaluasi terhadap beberapa responden, didapatkan bahwa nilai dari evaluasi kelompok 3 adalah 78\% (baik). User interface website yang dibuat telah sesuai dengan aturan emas kelompok 3 mengenai membuat interface yang konsisten. Poin continuity sudah baik, karena pada website telah dibangun sesuai dengan konsep dan berlanjut pada setiap halaman, seperti menu navigasi, footer, header, sidebar dan lainnya. Poin konsistensi sudah baik, antarmuka telah mempertahankan desain diluar dan didalam sistem, mengenai pewarnaan text, button, header, footer, navigation, carousel dan lainnya. Expectation sudah baik, antarmuka selalu menjaga hasil interaksi, seperti ukuran sidebar, header dan main page agar tetap sama saat halaman dirubah, begitu pula pada halaman pathfinding, dimana halaman Dijkstra dan Bidirectional Dijkstra memiliki desain antarmuka yang serupa sehingga pengguna akan lebih mudah menggunakan karena telah memiliki user experience sebelumnya. Poin attitude sudah cukup baik, karena antarmuka yang dibangun menggunakan vuetify.js memiliki desain yang menarik dan reactive. Poin predictable merupakan poin terakhir dari aturan ini, poin predictable sudah baik, karena desain antarmuka yang dibangun mudah untuk digunakan, dan memiliki desain yang konsisten sehingga mudah diprediksi saat pengguna ingin melakukan explorasi (Wardani, Darmawiguna and Sugihartini, 2019).

\section{KESIMPULAN}

Berdasarkan hasil evaluasi yang telah dilakukan dapat diketahui bahwa desain antarmuka yang dibuat memiliki nilai yang baik. Dapat diartikan desain antarmuka telah memenuhi kriteria aturan emas Theo Mandel. Dari 24 aturan evaluasi yang dinilai terdapat 9 aturan evaluasi mendapatkan nilai sangat baik dan 15 aturan mendapatkan nilai baik. Dengan total persentase nilai sebesar $79 \%$ (baik). Aturan emas Theo Mandel merupakan aturan evaluasi yang sederhana, relevan dan mengutamakan konsistensi. Tepat digunakan dalam evaluasi perancangan sistem berbasis web. Dengan desain antarmuka yang konsisten akan memberikan manfaat yang baik pada website atau sistem informasi yang memiliki kategori yang sama dan dapat meningkatkan user experience atau pengalaman pengguna. Penulis berharap kedepannya akan dapat merancang sebuah antarmuka yang lebih baik dan dapat menggunakan aturan evaluasi yang beragam, seperti penggunaan framework evaluasi. 


\section{DAFTAR PUSTAKA}

ABULFARAJ, A. dan STEELE, A., 2020. International Conference on HumanComputer Interaction. In: Coherent Heuristic Evaluation (CoHE): Toward Increasing the Effectiveness of Heuristic Evaluation for Novice Evaluators. Springer, Cham.

AGUSTIYO, H., 2018. Evaluasi Usability Aplikasi Pelayanan Masyarakat Jangka Joyoboyo Polres Kediri. In: Seminar Nasional Sistem Informasi dan Teknologi Informasi. pp.202206.

AJIE, W.S., ARIEF, S. dan AMIR, F.S., 2018. Evaluasi Usability Website UNRIYO Menggunakan System Usability Scale (Studi Kasus: Website UNRIYO). Jurnal Ilmiah Teknologi Informasi, 3(1).

AMINI, R.P., PRADNYANA, I.M.A. dan WIRAWAN, I.M.A., 2019. Evaluasi Usability pada Sistem Informasi Permohonan Kendaraan Dinas (Simonas) PT. PLN (Persero) Unit Induk Distribusi Bali UP3 Bali Utara Sesuai Iso 9241-11 dan Eight Golden Rules. Jurnal Pendidikan Teknologi dan Kejuruan.

ARYANDO, G.R., STEVEN, R.S. dan ALWIN, M.S., 2019. Perancangan Jalur Terpendek Evakuasi Bencana di Kawasan Boulevard Manado Menggunakan Algoritma Dijkstra. Jurnal Teknik Informatika, 14(2).

BAHRAEN, F., ROSIHAN, R. dan ABDUL, M., 2018. Implementasi Algoritma Dijkstra Untuk Penentuan Jalur Terpendek Pada Aplikasi Evakuasi Bencana Untuk Penyandang Disabilitas. Jurnal Informatika dan Komputer, 1(2).

BERNACK, J. dan BŁAŻEJCZYK, I., 2016. Responsive Web Design: Testing Usability of Mobile Web Applications. In: Asian Conference on Intelligent Information and Database Systems. Springer, Berlin, Heidelberg.pp.257-269.

CARLOS, R., 2019. Making Your First Progressive Web App. In: Building Progressive Web Applications with Vue.js. pp.1-46.

DIANATA, I. dan ADELIA, P., 2019. User-centred web design, usability and user satisfaction: The case of online banking websites in Iran. Applied Ergonomics, 81.

JEFFRY, A.P., LUKITO, E.N. dan RUDY, H., 2017. Rancangan Awal Website Berbasis User Centered Design (Kasus Website Universitas Janabadra Yogyakarta). In: Seminar Nasional Inovasi Teknologi.

NENTO, K., 2019. Evaluasi Aplikasi iJakarta Menggunakan Teori Golden Rules Of User Interface Design Theo Mandel. Jurnal Teknologi Informasi Indonesia (JTII).

ROLF, M. dan CHAUNCEY, W., 2020. How Professional Moderate Usability Tests.
Journal of Usability Studies, 15(4).

RUIZ, J. dan SERRAL, E., 2020. Unifying Functional User Interface Design Principles. International Journal of Human-Computer Interaction.

SUATKAB, A. dan SANTOSO, H.B., 2018. Evaluasi dan Pengembangan Alternatif Desain Antarmuka E-Campus STIKOM Ambon. Jurnal Sistem dan Teknologi Informasi (POSITIF).

TABANDEHPOUR, H., 2019. Cultural-based Interface Design. University of Lapland.

WARDANI, S., DARMAWIGUNA, I.G.M. dan Sugihartini, N., 2019. Usability Testing Sesuai Dengan ISO 9241-11 Pada Sistem Informasi Program Pengalaman Lapangan Universitas Pendidikan Ganesha Ditinjau Dari Pengguna Mahasiswa. Kumpulan Artikel Mahasiswa Pendidikan Teknik Informatika (KARMAPATI).

YASIN, A. dan YUMARLIN, M., 2016. Evaluasi Web UJB Menggunakan Golden Rules Of User Interface Design Theo Mandel. Seminar Nasional Teknologi Informasi dan Multimedia.

ZULFAN dan BAHAGIA, 2017. Sistem Informasi Data Korban Kebencanaan Berbasis Web. In: Seminar Nasional II USM. pp.110-113. 